\title{
Anticancer effects of a novel chroman analog in HeLa cells are associated with G2-phase arrest and mitochondrial-mediated apoptosis
}

\author{
HYUNJIN JEONG, YUMI SHIN And DONG-KYOO KIM \\ Department of Biomedicinal Chemistry and Institute of Basic Science, Inje University, \\ Gimhae, Gyeongsang 621-749, Republic of Korea
}

Received September 6, 2017; Accepted April 12, 2018

DOI: $10.3892 /$ or.2018.6404

\begin{abstract}
In the present study, the anticancer activity of 1-[(3S,4R)-2,2-dimethyl-3-oxo-4-(2-piperidonyl) chroman-6-yl]-3-phenylurea (S32) was investigated by testing its effect in vitro on the growth of HeLa cells. First, we showed that the $\mathrm{IC}_{50}$ value of $\mathrm{S} 32$ was $\sim 70 \mu \mathrm{M}$ by using WST-8 assay, and that it significantly inhibited the proliferation and viability of HeLa cells in a dose-dependent manner after $48 \mathrm{~h}$. Morphological changes in apoptotic cells included cellular shrinkage and nuclear condensation. The results of $\left[{ }^{3} \mathrm{H}\right]$-thymidine incorporation and flow cytometric analysis indicated that $\mathrm{S} 32$ induced inhibition of DNA replication and G2-phase cell cycle arrest. Moreover, S32 induced the levels of reactive oxygen species (ROS) and decreased the mitochondrial membrane potential (MMP) in a time-dependent manner. Using Annexin V-FITC/propidium iodide (PI) dual staining assay, we found that S32 noticeably increased early apoptosis in HeLa cells in a time-dependent manner. The result of western blot analysis showed that the apoptotic induction was associated with an increase in Bax levels and a decrease in Bcl-2 levels, which led to activation of caspase-8, -9 and -3 . Taken together, our findings demonstrated that S32 induces mitochondrial-mediated apoptosis in HeLa cells and suggest that S32 has potential as an anticancer drug.
\end{abstract}

\section{Introduction}

Cervical carcinoma is the second most prevalent female cancer and the most common malignancy in terms of both incidence

Correspondence to: Professor Dong-Kyoo Kim, Department of Biomedicinal Chemistry and Institute of Basic Science, Inje University, 607 Aubang-dong, Gimhae, Gyeongsang 621-749, Republic of Korea

E-mail: chemkdg@inje.ac.kr

Key words: chroman analogs, cell cycle, apoptosis, reactive oxygen species and mortality worldwide (1). More than $80 \%$ of the cervical cancers occur in developing countries (2). Several therapies are used to treat the disease, but each of them has adverse effects (3). Therefore, the development of a safer and more efficient chemotherapeutic treatment for cervical carcinoma is very important.

The process of apoptosis or programmed cell death is tightly controlled and it plays important roles in many biological processes ranging from fetal development to adult tissue homeostasis (4). Apoptosis is characterized by morphological changes, including cell shrinkage, nuclear reorganization, blebbing of active membrane, and fragmentation of the cell into membrane-enclosed vesicles (5). As malignant cells suppress this response to survive, apoptosis has been an important focus of the current cancer research. Apoptosis can be initiated through the intrinsic (mitochondrial-mediated) and extrinsic (death receptor-mediated) pathway (6-8). Several important events occur in the mitochondria right after intrinsic apoptotic stimulation, including the release of pro-apoptotic factors such as cytochrome $c$ from the mitochondria into the cytoplasm $(9,10)$. In the cytosol, cytochrome $c$ interacts with apoptotic protease activating factor-1 (Apaf-1), leading to the activation of the cysteine-aspartic protease caspase-9, which activates caspase- 3 followed by activation of the rest of the caspase cascade, leading to programmed cell death (11). In addition, the activation of mitochondria and the release of regulatory factors from the mitochondrial intermembrane space control a number of Bcl-2 family of regulatory proteins downstream (12-14). Some of these proteins such as Bcl-2 are anti-apoptotic and prevent the release of cytochrome $c$, whereas others such as Bax promote the release of cytochrome $c$ (15). The extrinsic pathway involves the binding of ligands of the tumor necrosis factor (TNF) superfamily to cell surface death receptors and the subsequent activation of membrane-proximal caspases (caspase-8 and -10) (16).

Reactive oxygen species (ROS) [e.g., superoxide anions $\left(\mathrm{O}_{2} \cdot^{-}\right)$, hydrogen peroxide $\left(\mathrm{H}_{2} \mathrm{O}_{2}\right)$, and hydroxyl radicals $(\mathrm{OH} \cdot)]$ are by-products of cellular metabolic pathways and are crucial secondary messengers in various intracellular signaling pathways $(17,18)$. Recently, it has become clear that ROS play a significant role in the cause of apoptotic cell death 
under physiological as well as pathological conditions, and that interestingly, mitochondria are both the source and the target of ROS $(19,20)$. Several investigators suggested evidence that intracellular ROS can directly cause the mitochondrial permeability transition activation, loss of mitochondrial membrane potential (MMP), and release of cytochrome $c$ from mitochondria $(21,22)$.

The cell cycle is deregulated in tumors, causing lack of differentiation and aberrant growth of cells (23-25). The cell cycle regulates cell division, differentiation, growth and programmed cell death (26). Many anticancer agents have been developed to arrest the cell cycle at specific checkpoints, thereby causing apoptotic cell death (27). G2 or pre-mitotic phase is the third and final subphase of interphase in the cell cycle, directly preceding mitosis and following successful completion DNA replication during S phase. G2 ends with the onset of prophase, the first phase of mitosis, during which the chromatin condenses into chromosomes. A series of chroman analogs previously reported as potassium channel openers were examined for their in vitro growth inhibitory effect on human glioma cells (28). We evaluated the cytotoxic effect of six chroman analogs that were kindly provided by Dr D.S. Shin on HeLa cells using the WST-8 assay, and found that 1-[(3S,4R)-2,2-dimethyl-3-oxo-4-(2-piperidonyl) chroman-6-yl]-3-phenylurea (S32) (Fig. 1) showed the strongest effect. Notably, we found that chroman derivatives containing a phenylurea group were more cytotoxic than derivatives without this group (Table I), showing that this group is important for cytotoxicity (21). Phenylurea-type 2,2-dimethylchromans have been identified as a new class of potential antitumor agents for an innovative therapeutic approach for high-grade glioma (28). However, the underlying molecular mechanisms attributed to the growth inhibitory and cytotoxic effects of S32 are poorly understood. In this study, we investigated the anticancer effect of S32 derivatives in HeLa cells to identify appropriate novel candidate antitumor drugs.

\section{Materials and methods}

Chemicals. The Annexin V-FITC kit and propidium iodide (PI)/RNase staining buffer for apoptosis were obtained from BD Biosciences (Franklin Lakes, NJ, USA). Eagle's minimum essential medium (EMEM), penicillin-streptomycin and trypsin-EDTA were obtained from HyClone (HyClone: GE Healthcare Life Sciences, Logan, UT, USA). Fetal bovine serum (FBS) was purchased from Gibco-BRL (Gibco-BRL: Thermo Fisher Scientific, Inc., Waltham, MA, USA). Cell Counting kit-8 (CCK-8) was obtained from Dojindo Molecular Technologies, Inc. (Kumamoto, Japan). Dimethyl sulfoxide (DMSO) and phosphate-buffered saline (PBS, $\mathrm{pH}$ 7.4) were purchased from Sigma-Aldrich Chemical Co. (Sigma-Aldrich Chemical Co.: Merck KGaA, Darmstadt, Germany). All other chemicals were of analytical reagent grade.

Cell lines. HeLa cells obtained from the American Type Culture Collection (ATCC) (Manassas, VA, USA) were cultured in EMEM supplemented with 10\% FBS and $1 \%$ penicillin-streptomycin at $37^{\circ} \mathrm{C}$ in a humidified atmosphere with $5 \% \mathrm{CO}_{2}$.

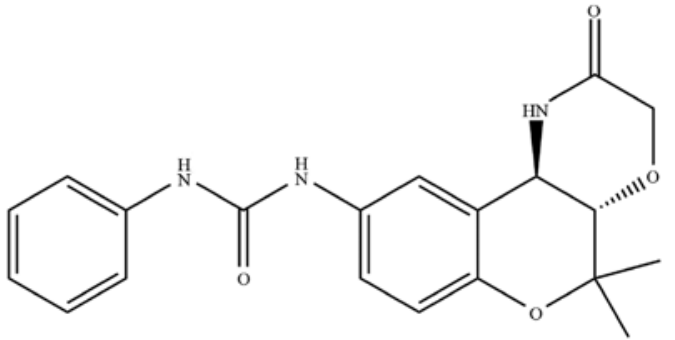

Figure 1. Chemical structure of 1-[(3S,4R)-2,2-dimethyl-3-oxo-4-(2-piperidonyl)chroman-6-yl]-3-phenylurea $\left(\mathrm{C}_{20} \mathrm{H}_{21} \mathrm{~N}_{3} \mathrm{O}_{4}\right)(\mathrm{S} 32)$.

Table I. Evaluation of the cytotoxic effects of phenylurea-including compounds and non-including compounds (mother compound) on HeLa cells.

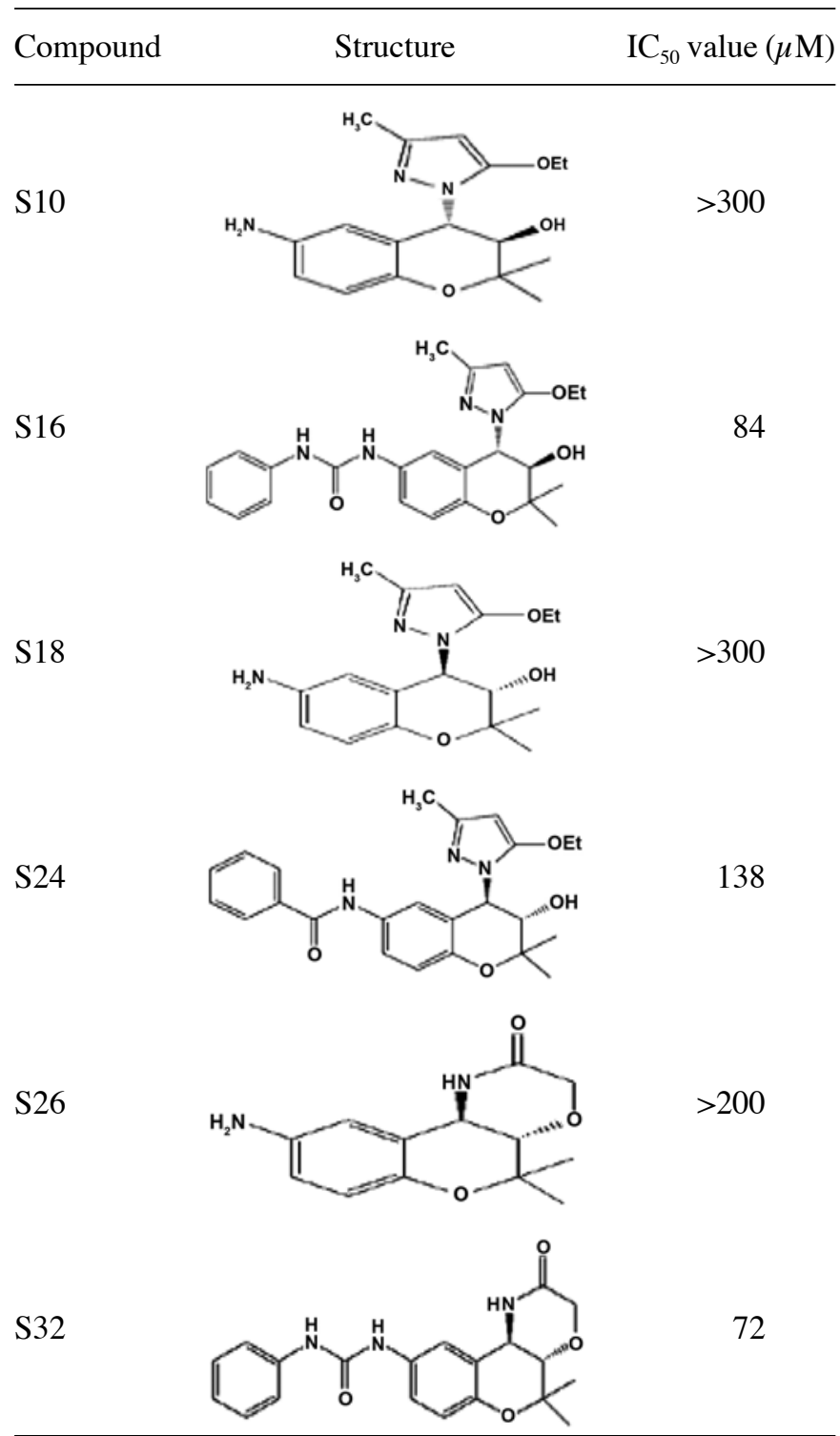

Preparation of chroman analog sample. 1-[(3S,4R)-2,2-dimethyl-3-oxo-4-(2-piperidonyl)chroman-6-yl]-3-phenylurea (S32) and other chroman analogs (S10, S16, S18, S24, and S26) were obtained from the laboratory of Dr D.S. Shin (Changwon National University). The stock solutions of all chroman 
analogs were prepared in DMSO as $100 \mathrm{mM}$ and maintained at $4^{\circ} \mathrm{C}$. Further dilutions were made immediately prior to each experiment.

Cell viability and proliferation assay. HeLa cells were seeded at $5 \times 10^{3}$ cells into each well of a 96-well microplate. After $24 \mathrm{~h}$, media were replaced with fresh media containing the various concentrations $(20,40$ and $80 \mu \mathrm{M})$ of S32. The plate was incubated for a further $48 \mathrm{~h}$. Then, CCK-8 reagent $(10 \mu \mathrm{l})$ was added to each well of the plate and incubated for $2 \mathrm{~h}$. The cell viability was assessed using WST-8 [2-(2-methoxy-4-nitrophenyl)-3-(4nitrophenyl)-5-(2,4-disulfophenyl)- $2 \mathrm{H}$-tetrazolium] according to the manufacturer's recommendations (29). The optical density for living cells was read at $450 \mathrm{~nm}$ using a multi-microplate reader (Synergy HT; BioTek Instruments, Inc., Winooski, VT, USA). For determination of cell proliferation, cells were seeded at $5 \times 10^{3}$ cells $/ \mathrm{ml}$ media in 96-well microplates and treated with or without $\mathrm{S} 32(70 \mu \mathrm{M})$ for various times $(0,12$, 24, 36, 48 and 60 h). Each experiment was repeated at least three times.

Measurement of apoptotic cell morphology. HeLa cells were distributed $\left(1 \times 10^{5}\right.$ cells/well) into a 6 -well plate and allowed to stand overnight. The cells were treated with $\mathrm{S} 32(70 \mu \mathrm{M})$ for 24 and $48 \mathrm{~h}$. Wells that were not treated with $\mathrm{S} 32$ received an equivalent volume of DMSO $(<0.1 \%)$ used as a control. Phase-contrast images were captured with a Nikon Phase Contrast-2, ELWD 0.3 inverted microscope.

Measurement of ROS. Production of ROS was assessed using the fluorescent indicator $2^{\prime}, 7^{\prime}$-dichlorodihydrofluorescein diacetate $\left(\mathrm{H}_{2} \mathrm{DCF}-\mathrm{DA}\right)$, a cell-permeable indicator for ROS, shown to react with $\mathrm{H}_{2} \mathrm{O}_{2}(30) . \mathrm{H}_{2}$ DCF-DA is oxidized to highly green fluorescent 2 ',7'-dichlorofluorescein (DCF) via the generation of ROS. HeLa cells $\left(3 \times 10^{5}\right.$ cells in a $60-\mathrm{mm}$ dish) treated with $(70 \mu \mathrm{M})$ or without $\mathrm{S} 32$ were collected by trypsinization and centrifugation at $300 \mathrm{x} \mathrm{g}$ for $5 \mathrm{~min}$. The pellets were washed with cold PBS and stained with $2 \mu \mathrm{l}$ of $\mathrm{H}_{2} \mathrm{DCF}-\mathrm{DA}$ for $30 \mathrm{~min}$ at $37^{\circ} \mathrm{C}$ in a dark room. Relative fluorescence intensities were observed using the FACSCalibur flow cytometer (BD Biosciences, Franklin Lakes, NJ, USA) and analyzed by CellQuest Pro software (Becton-Dickinson: BD Biosciences, Franklin Lakes, NJ, USA) with the FL-1 channel (green) set to $530 \mathrm{~nm}$.

Measurement of MMP $(\Delta \Psi m)$. Changes in MMP were detected by using a fluorescent probe, rhodamine 123 (RH-123; Molecular Probes, Inc.; Thermo Fisher Scientific, Inc., Eugene, OR, USA). HeLa cells $\left(3 \times 10^{5}\right.$ cells in a $60-\mathrm{mm}$ dish) treated with $(70 \mu \mathrm{M})$ or without $\mathrm{S} 32$ were collected by trypsinization and centrifugation at $300 \mathrm{x}$ g for $5 \mathrm{~min}$. The pellets were washed with cold PBS and stained with $5 \mu \mathrm{l}$ of rhodamine and intensities were observed by the FACSCalibur flow cytometer (BD Biosciences) and analyzed by CellQuest software (Becton-Dickinson: BD Biosciences) with the FL-1 channel.

$\left[{ }^{3} \mathrm{H}\right]$-thymidine incorporation assay. The $\left[{ }^{3} \mathrm{H}\right]$-thymidine incorporation assay was performed as described in a previously study (31). HeLa cells were cultured in 6-well plates in growth media (EMEM $+10 \% \mathrm{FBS}+1 \%$ penicillin-streptomycin). After the cells were grown to $70-80 \%$ confluence, they were rendered quiescent by incubation for $24 \mathrm{~h}$ in EMEM containing $2 \%$ FBS. Cells were then treated with $(70 \mu \mathrm{M})$ or without S32 in EMEM supplemented with $10 \%$ FBS. After incubation for 21 or $45 \mathrm{~h},\left[{ }^{3} \mathrm{H}\right]$-thymidine was added at $1 \mu \mathrm{Ci} / \mathrm{ml}(1 \mu \mathrm{Ci}=37 \mathrm{kBq})$ and further incubated for $3 \mathrm{~h}$. Incorporated $\left[{ }^{3} \mathrm{H}\right]$-thymidine was measured by using a Liquid Scintillation Analyzer (Tris-Carb 2910TR; PerkinElmer, Inc., Waltham, MA, USA).

Cell cycle arrest analysis. HeLa cells $\left(3 \times 10^{5}\right.$ cells in a $60-\mathrm{mm}$ Petri dish) treated with $(70 \mu \mathrm{M})$ or without S32 were collected by trypsinization and washed with cold PBS by centrifugation at $412 \mathrm{x} \mathrm{g}$ for $6 \mathrm{~min}$. After suspension in PBS and fixation with $70 \%$ ethanol (v/v), samples were washed with cold PBS and stained with PI/RNase staining buffer for $15 \mathrm{~min}$ at room temperature. The number of cells in the different cell cycle phases was analyzed using a FACSCalibur flow cytometer analysis system (BD Biosciences) and 20,000 events were analyzed for each sample. The percentage of cells in the different phases was determined using ModFit software (Verity Software House, Inc., Topsham, ME, USA).

Annexin V-FITC/PI apoptotic analysis. HeLa cells ( $3 \times 10^{5}$ cells in a $60-\mathrm{mm}$ dish) treated with $(70 \mu \mathrm{M})$ or without S32 were collected by trypsinization and washed with ice-cold PBS via centrifugation at 2,500 x g for $3 \mathrm{~min}$. Subsequently, $1 \times 10^{5}$ cells were resuspended in $100 \mu \mathrm{l}$ of binding buffer and stained with $5 \mu \mathrm{l}$ of Annexin V-FITC and $10 \mu \mathrm{l}$ of PI $(50 \mu \mathrm{g} / \mathrm{ml})$ for $15 \mathrm{~min}$ at room temperature in the dark. Analysis was performed using FACSCalibur flow cytometer (BD Biosciences) with 10,000 events each time. The data were analyzed by CellQuest Pro software (Becton-Dickinson: BD Biosciences).

Protein extraction and western blot analysis. After the treatment of HeLa cells ( $1 \times 10^{5}$ cells in a $150-\mathrm{mm}$ dish) with $(70 \mu \mathrm{M})$ or without $\mathrm{S} 32$, total cell lysates and cytosolic fractions were prepared as described in a previous study (32). Protein contents of the lysates were determined by the Bradford protein assay. Proteins $(20 \mu \mathrm{g})$ were separated by SDS-PAGE and transferred onto nitrocellulose membranes by western blot analysis. The following primary polyclonal antibodies were used: $\beta$-actin (cat. no. 4967), pro-caspase- 8 (cat. no. 4790), pro-caspase-9 (cat. no. 9502), Bcl-2 (cat. no. 2872) (1:1,000 dilution; rabbit; Cell Signaling Technology, Inc., Danvers, MA, USA), pro-caspase-3 (1:300; mouse; cat. no. sc-7272; Santa Cruz Biotechnology, Inc., Santa Cruz, CA, USA) and Bax (1:1,000; mouse; cat. no. 556467; BD Biosciences, San Diego, CA, USA). The results were quantified using ImageJ v.1.43 software (National Institutes of Health, Bethesda, MD, USA).

Statistical analysis. Each experiment was repeated at least three times. The results are expressed as the mean \pm standard deviation (SD) values of three independent experiments. Statistical analysis was performed by one-way analysis of variation (ANOVA). The criterion for significance was set at $\mathrm{P}<0.05$. For the statistical and graphical evaluations, Microsoft Excel 2007 was used. 


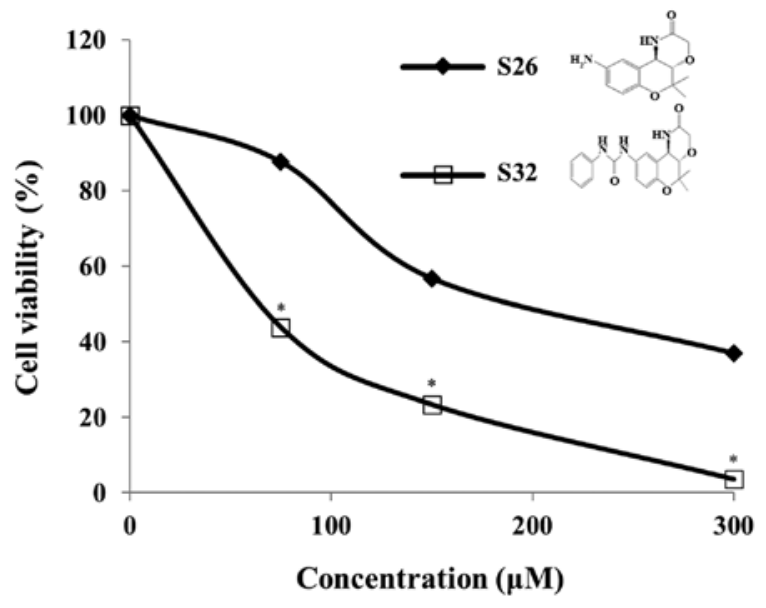

Figure 2. Cytotoxic effect of S26 and S32 on HeLa cells. HeLa cells were treated with $0,75,150,300 \mu \mathrm{M}$ of S26 and S32 for $48 \mathrm{~h}$. Cell viability was measured by WST- 8 assay. Results are expressed as mean \pm SD, $n=3$. ${ }^{*} \mathrm{P}<0.05$, significantly different from the control at the same level. SD, standard deviation.

\section{Results}

S32 inhibits the viability and proliferation of HeLa cells. In the present study, we evaluated the cytotoxic effect of chroman compounds, S26 and S32, at different concentrations $(75,150$, and $300 \mu \mathrm{M})$ on HeLa cells. After incubation with the chroman compounds for $48 \mathrm{~h}$, we observed a significant $(\mathrm{P}<0.05)$ concentration-dependent cytotoxicity of S32 compared to that observed with the control. In addition, we found that S32 inhibited cell viability to a greater extent than the mother compound S26 (Fig. 2). Therefore, we selected $\mathrm{S} 32$ for further study. As shown in Fig. 3A, the $\mathrm{IC}_{50}$ value of S32 was $70 \mu \mathrm{M}$. Treatment of HeLa cells with $70 \mu \mathrm{M}$ of S32 for various time periods $(0,12,24,36,48$ and $60 \mathrm{~h})$ showed that their growth gradually increased until $12 \mathrm{~h}$ and started to decrease at $24 \mathrm{~h}$, whereas untreated cells maintained exponential proliferation (Fig. 3B). These data demonstrated that $\mathrm{S} 32$ decreased HeLa cell viability in a concentration- and time-dependent manner.

S32 induces apoptosis-related cell morphology. Morphological changes are important characteristics of apoptotic cells. Microscopic analysis revealed the occurrence of apoptosis in cells treated with $70 \mu \mathrm{M}$ of S32 for various durations (Fig. 4). As shown in Fig. 4A and C, non-treated HeLa cells proliferated regularly throughout the culture plate and grew to near confluence. After $24 \mathrm{~h}$ of treatment with S32, some cells were detached from the plate but the majority of the attached cells maintained a normal shape (Fig. 4B). After $48 \mathrm{~h}$ of treatment, the number of floating cells increased and the attached cells showed cell shrinkage and disruption, indicating apoptosis (Fig. 4D).

S32 induces ROS production and depolarization of the $M M P$. Several studies have reported that ROS can activate the mitochondrial permeability transition and loss of MMP (33). By using the cell permeable dye, we showed that S32 has the capacity to induce the generation of intracellular
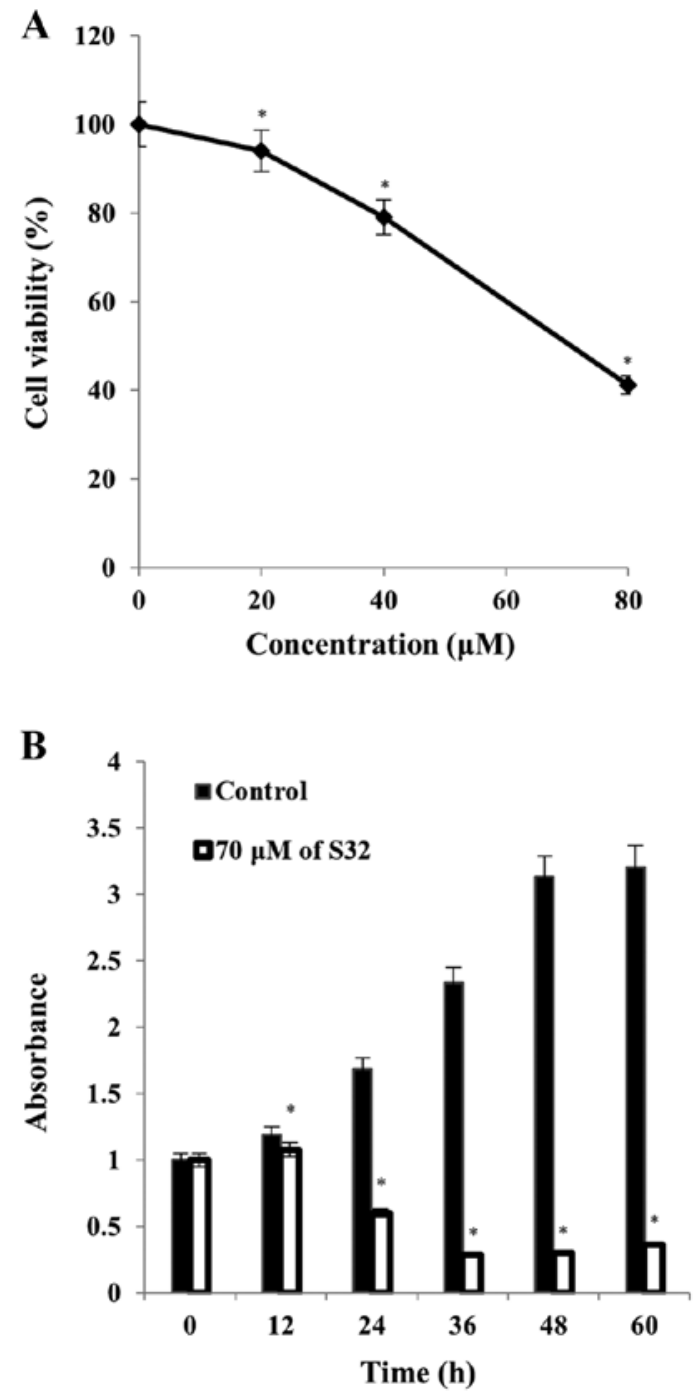

Figure 3. Effect of S32 on cytotoxicity and proliferation of HeLa cells. (A) HeLa cells were treated with $0,20,40$ and $80 \mu \mathrm{M}$ of S32 for $48 \mathrm{~h}$. (B) HeLa cells were treated with $70 \mu \mathrm{M}$ of S32 for various times $(0,12$, 24, 36, 48 and 60 h). Cell viability was measured by WST- 8 assay. Results are expressed as mean $\pm S D, n=3 .{ }^{*} P<0.05$, significantly different from the control at the same level. SD, standard deviation.

ROS. Treatment of the HeLa cells with $70 \mu \mathrm{M}$ of $\mathrm{S} 32$ for $1 \mathrm{~h}$ induced ROS generation compared to that observed with the control. As shown in Fig. 5, the mean $\mathrm{H}_{2}$ DCF-DA fluorescence increased from 109.26 to 341.67 after treatment with S32 for $1 \mathrm{~h}$. Apoptosis induces mitochondrial membrane depolarization. A decrease in $\mathrm{H}_{2}$ DCF-DA fluorescence suggests the loss of MMP. We examined S32-induced MMP loss in HeLa cells. As shown in Fig. 6, the mean RH-123 fluorescence significantly $(\mathrm{P}<0.05)$ increased from $91.93(0 \mathrm{~h})$ to $99.73(12 \mathrm{~h})$ and then significantly $(\mathrm{P}<0.05)$ decreased to 66.75 after treatment with S32 for $24 \mathrm{~h}$, respectively, suggesting that S32 induced apoptosis.

S32 promotes inhibition of DNA replication and induction of G2 phase cell cycle arrest in HeLa cells. To identify that S32 affects cells at the DNA level, we analyzed DNA replication in cells treated with $70 \mu \mathrm{M}$ of $\mathrm{S} 32$ by using a $\left[{ }^{3} \mathrm{H}\right]$-thymidine incorporation assay. As shown in Fig. $7 \mathrm{~A},\left[{ }^{3} \mathrm{H}\right]$-thymidine incorporation was significantly $(\mathrm{P}<0.05)$ reduced in $\mathrm{HeLa}$ 
A
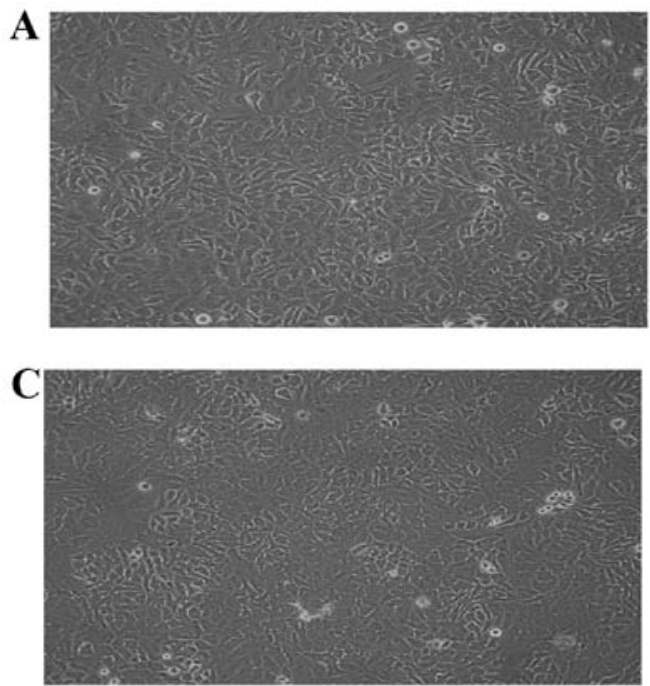
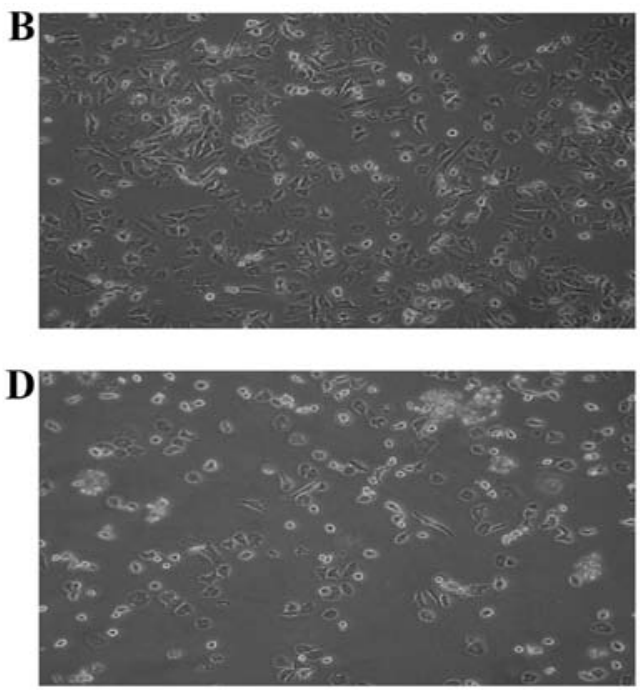

Figure 4. Induction of morphological change in HeLa cells treated with S32 for different times ( 0,24 and $48 \mathrm{~h})$. HeLa cells were not treated with S32 for (A) $24 \mathrm{~h}$ and (C) $48 \mathrm{~h}$. HeLa cells were treated with S32 (70 $\mu \mathrm{M})$ for (B) $24 \mathrm{~h}$ and (D) $48 \mathrm{~h}$. Magnification, x160. All the experiments were performed in triplicate and gave similar results.

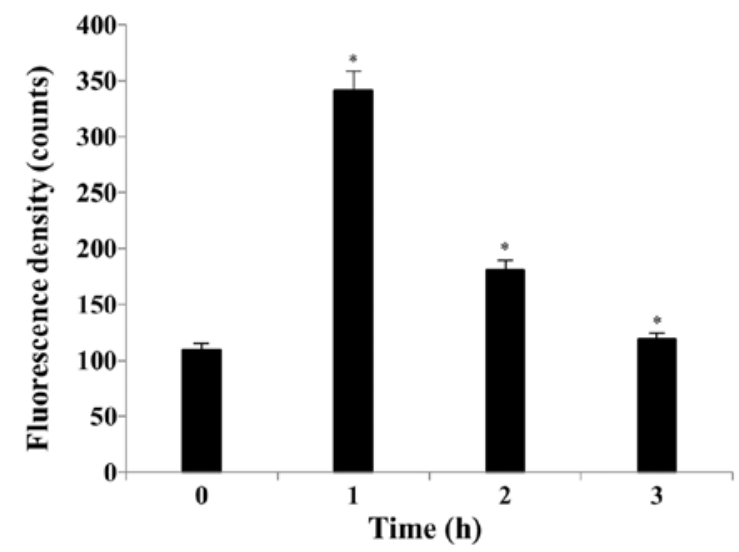

Figure 5. Effect of S32 on ROS generation in HeLa cells at different times $(0,1,2$ and $3 \mathrm{~h})$. HeLa cells were treated with $70 \mu \mathrm{M}$ of S32 for various times. Results are expressed as mean $\pm \mathrm{SD}, \mathrm{n}=3$. ${ }^{*} \mathrm{P}<0.05$, significantly different from the control at the same level. ROS, reactive oxygen species; SD, standard deviation.

cells treated with $\mathrm{S} 32$, suggesting that DNA replication was inhibited in a time-dependent manner.

Cell proliferation and apoptosis are controlled by regulators of cell cycle progression and apoptotic impulses $(34,35)$. The appearance of a sub- $\mathrm{G}_{0} / \mathrm{G}_{1}$ peak, also termed apoptotic peak, on flow cytometric DNA content histograms is thought to be one of the features of cells undergoing apoptosis (36). To examine the effect of S32 on cell cycle progression, HeLa cells were treated with $70 \mu \mathrm{M}$ of S32 for 24 or $48 \mathrm{~h}$, and analyzed by using flow cytometry. Treatment with S32 (Fig. 7Bb and d) increased the fraction of G2-phase cells compared to the untreated cells (Fig. 7Ba and d). In addition, treatment of S32 increased the percentage of sub-G1 phase (apoptotic) cells in a time-dependent manner. These data demonstrated that S32 induced G2 phase cell cycle arrest in HeLa cells.

S32 induces apoptosis in HeLa cells. To confirm that apoptosis was induced by S32, HeLa cells were treated

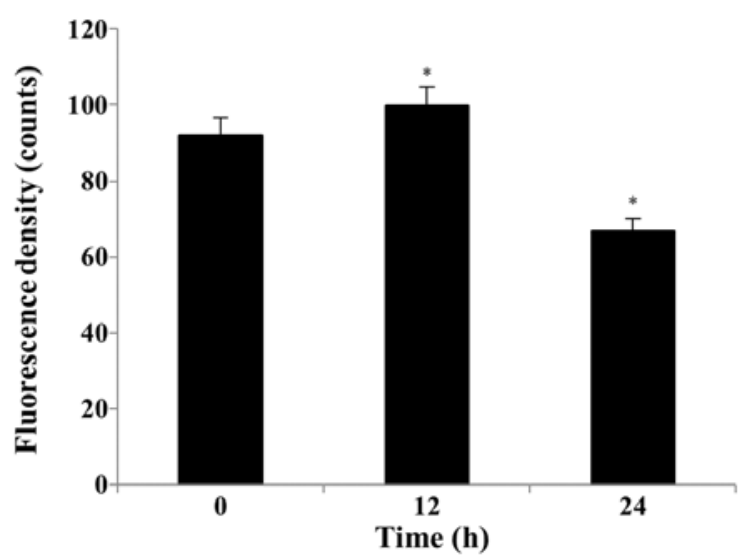

Figure 6. Effect of $\mathrm{S} 32$ on intracellular MMP $(\Delta \Psi \mathrm{m})$ in HeLa cells was obtained by RH-123 staining assay. HeLa cells were treated with S32 $(70 \mu \mathrm{M})$ for various times $(0,12$ and $24 \mathrm{~h})$. All the experiments were performed in triplicate and gave similar results. ${ }^{*} \mathrm{P}<0.05$, significantly different from the control at the same level. MMP, mitochondrial membrane potential; RH-123, rhodamine 123.

with $70 \mu \mathrm{M}$ of $\mathrm{S} 32$ for 24 or $48 \mathrm{~h}$ and were then analyzed using flow cytometry after staining with Annexin V-FITC and PI. The staining of cells with Annexin V-FITC and PI is used to distinguish and quantify non-apoptotic (Annexin V-FITC-/PI'), early apoptotic (Annexin V-FITC ${ }^{+} / \mathrm{PI}^{-}$), and late apoptotic (or necrotic) (Annexin $\mathrm{V}-\mathrm{FITC}^{+} / \mathrm{PI}^{+}$and Annexin V-FITC-/PI ${ }^{+}$) cells (37). Treatment with S32 increased the fraction of apoptotic cells (Fig. 8B and D) compared to the non-treated cells (Fig. 8A and C), confirming that S32 induced apoptosis in HeLa cells in a time-dependent manner.

S32 induces mitochondrial-mediated apoptosis. The Bcl-2 family of proteins plays a crucial role in the regulation of cell life and death (38). The ratio between pro- (e.g., Bax) and anti-apoptotic (e.g., Bcl-2) proteins determines, in part, the susceptibility of cells to a death signal (39). We evaluated the effect of S32 treatment on the Bax/Bcl-2 ratio by using western 
A

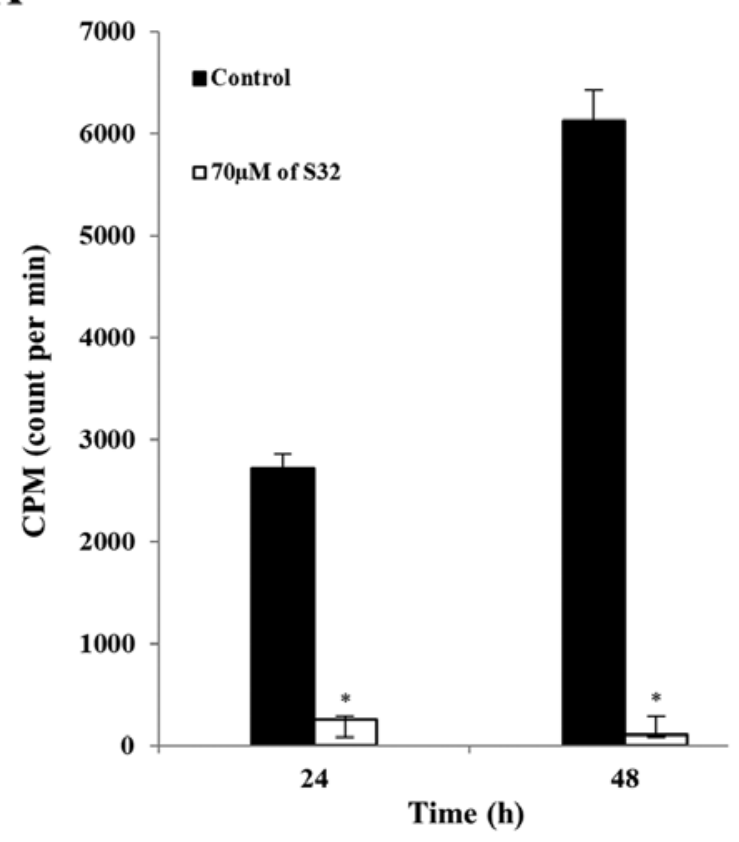

B a

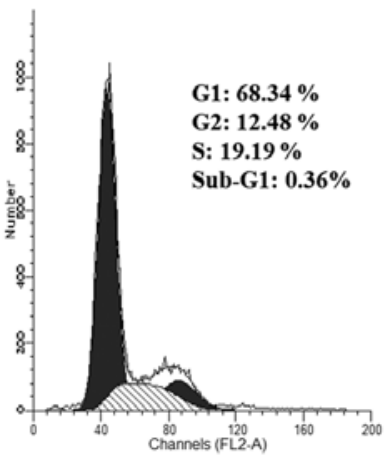

C

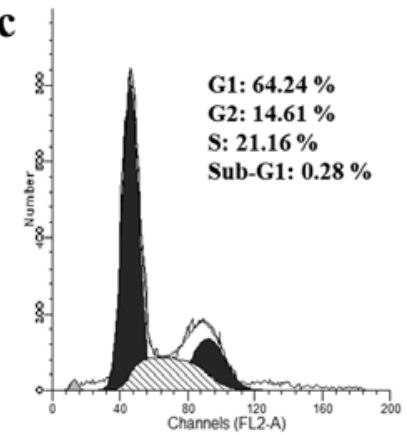

b

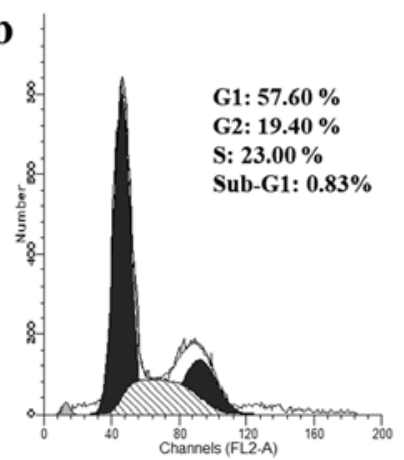

d

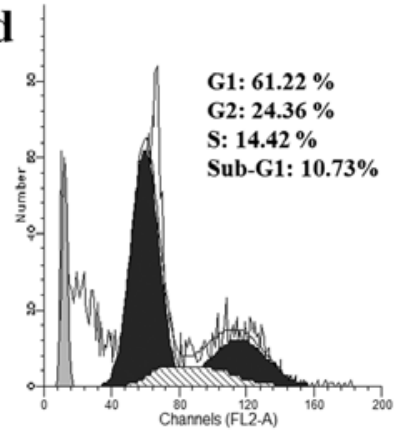

Figure 7. Inhibitory effect of S32 on $\left[{ }^{3} \mathrm{H}\right]$-thymidine incorporation and induction of S32 on cell cycle arrest of HeLa cells. (A) HeLa cells were treated with $70 \mu \mathrm{M}$ of S32 for 24 and $48 \mathrm{~h}$, respectively. Results are expressed as mean $\pm \mathrm{SD}, \mathrm{n}=3$. ${ }^{*} \mathrm{P}<0.05$, significantly different from the control at the same level. (B) HeLa cells were not treated with S32 for (a) $24 \mathrm{~h}$ and (c) $48 \mathrm{~h}$, or HeLa cells were treated with $70 \mu \mathrm{M}$ of S32 for (b) $24 \mathrm{~h}$ and (d) $48 \mathrm{~h}$. S32 treatment induced G2-phase cell cycle arrest in a time-dependent manner. Data were determined by flow cytometry. The data are representative of three independent experiments. SD, standard deviation.
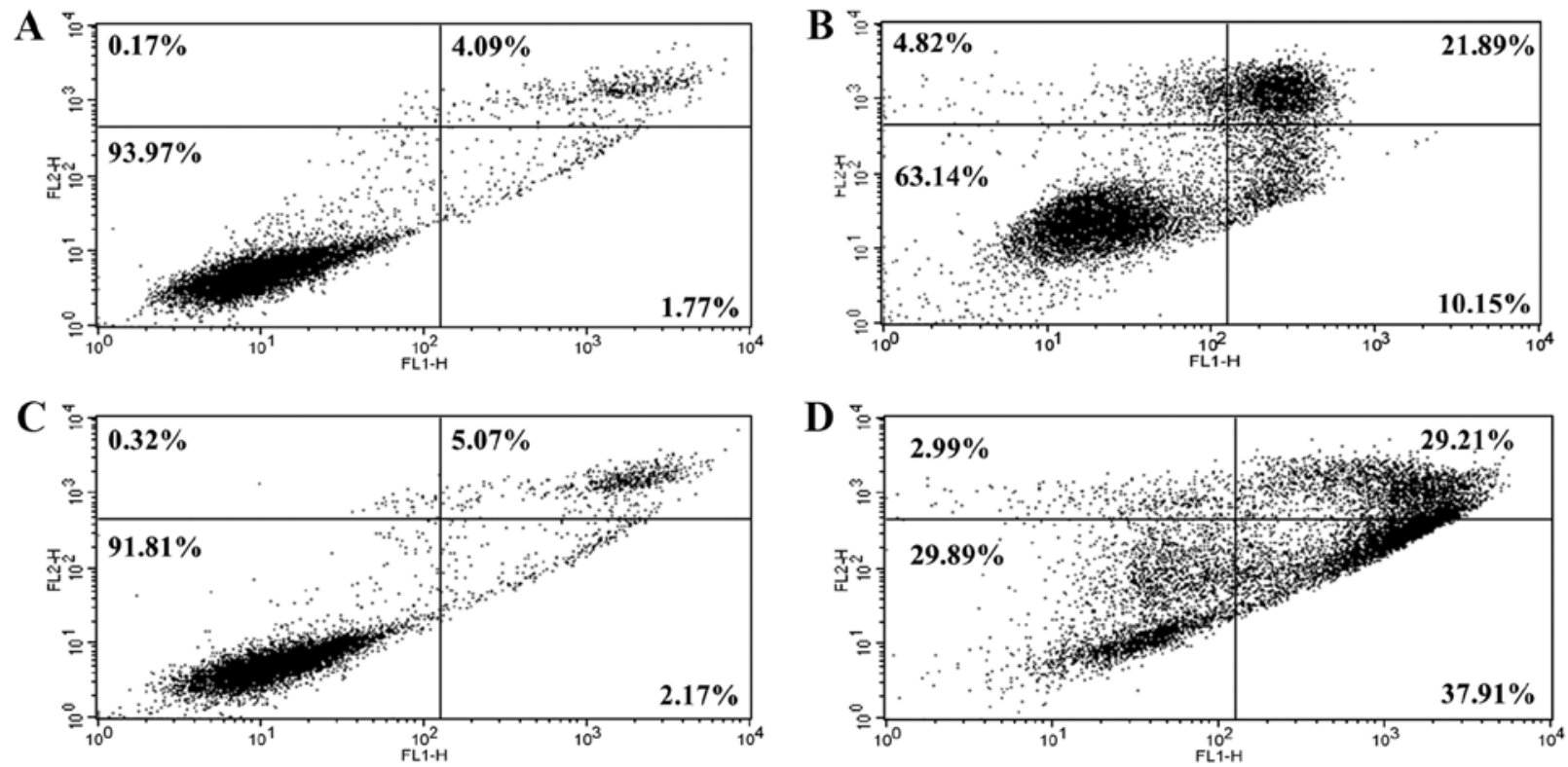

Figure 8. Induction of apoptosis following treatment of S32 in HeLa cells. HeLa cells were not treated with S32 for (A) $24 \mathrm{~h}$ and (C) $48 \mathrm{~h}$, or HeLa cells were treated with S32 (70 $\mu \mathrm{M})$ for (B) $24 \mathrm{~h}$ and (D) $48 \mathrm{~h}$. Data were obtained by flow cytometric analysis of Annexin V-FITC/PI double-staining assay. All the experiments were performed in triplicate and gave similar results. PI, propidium iodide.

blot analysis. As shown in Fig. 9, the Bcl-2 level decreased while the Bax level increased with time in cells treated with $\mathrm{S} 32$, indicating that the $\mathrm{Bax} / \mathrm{Bcl}-2$ ratio significantly $(\mathrm{P}<0.05)$ increased in a time-dependent manner (Fig. 9B).

In response to apoptotic stimuli, the outer mitochondrial membrane becomes permeable, resulting in the release of cytochrome $c$ and other caspase activators (11). We evaluated whether the caspase-dependent mitochondrial-mediated pathway is involved in S32-induced apoptosis to determine the underlying molecular mechanism of this process. The pro-caspase- 9 and -3 levels were markedly decreased in cells treated with S32, while the pro-caspase-8 level decreased 

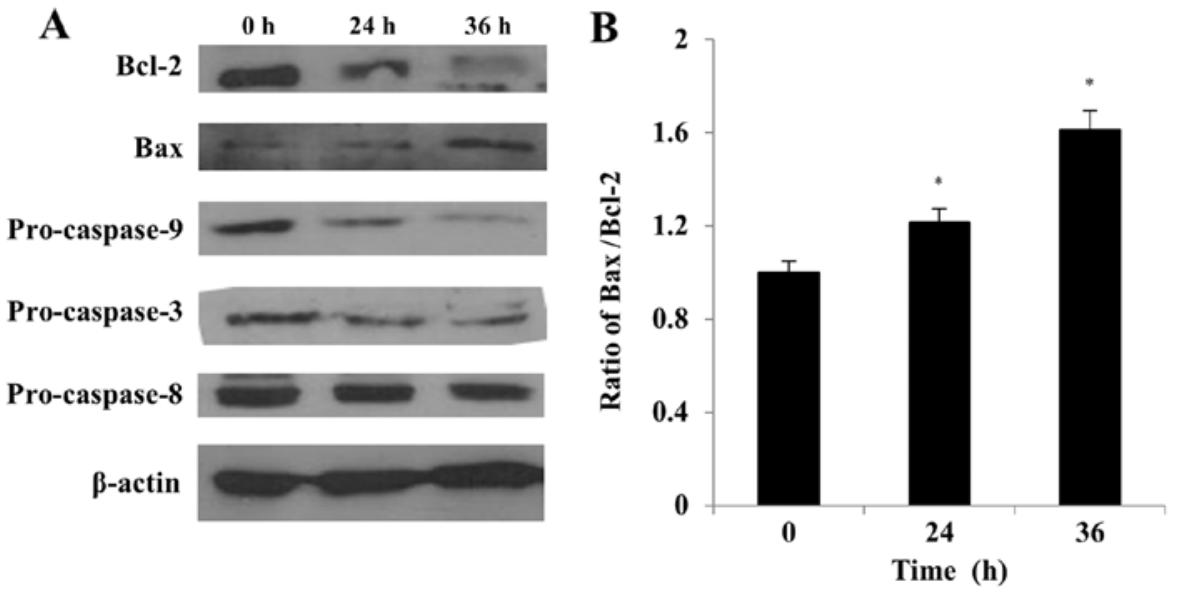

Figure 9. Induction of protein activation in S32-induced apoptosis in HeLa cells. HeLa cells were treated with S32 (70 $\mu \mathrm{M})$ for 0,24 and $48 \mathrm{~h}$ and levels of apoptosis-associated proteins were determined by western blot analysis. (A) Protein expression levels of pro-caspase- 9 , -3 , and -8 , Bcl-2 and Bax. (B) The ratio of $\mathrm{Bax} / \mathrm{Bcl}-2$. Results are expressed as mean $\pm \mathrm{SD}, \mathrm{n}=3 .{ }^{*} \mathrm{P}<0.05$, significantly different from the control at the same level. SD, standard deviation.

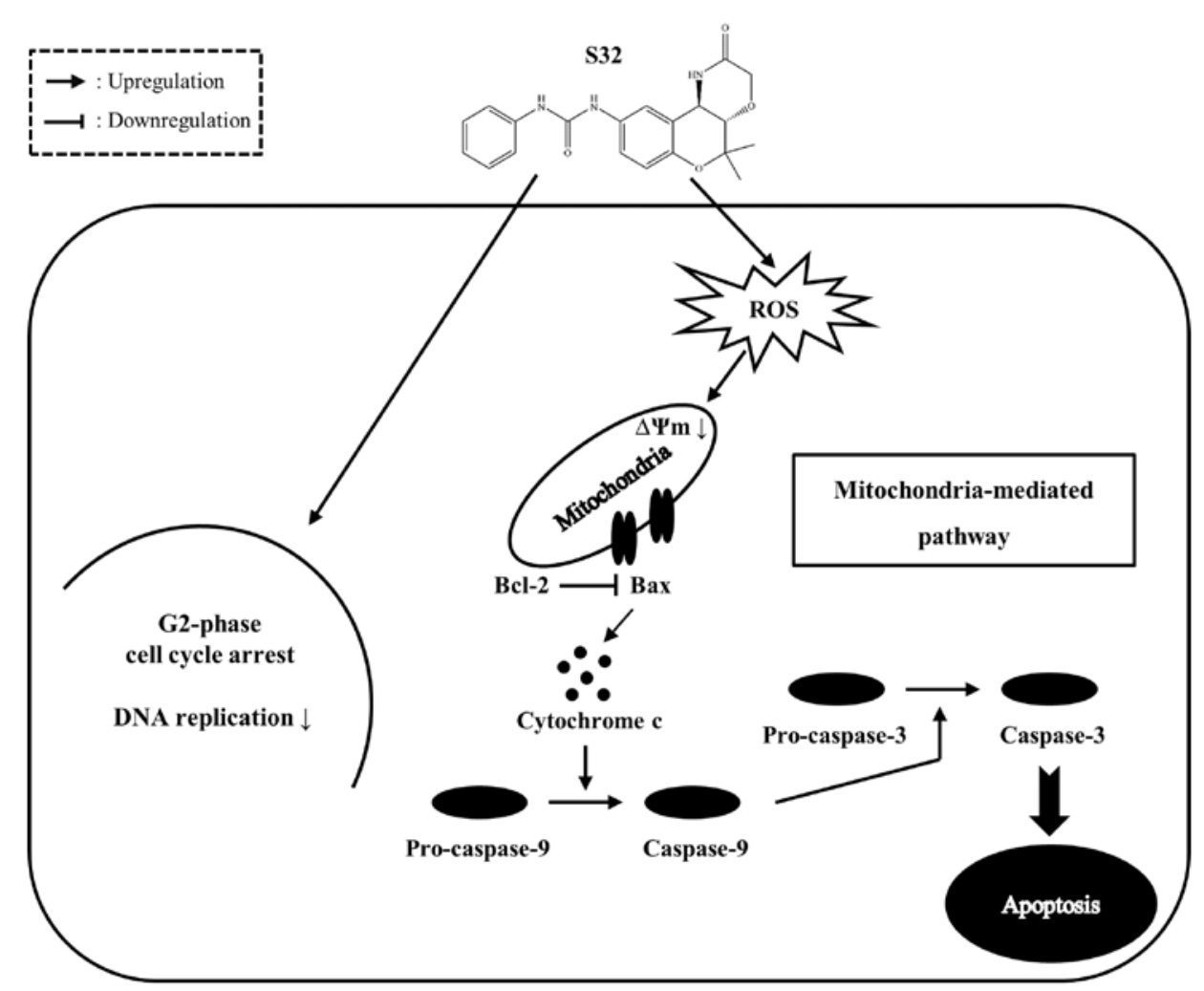

Figure 10. The proposed mechanism of apoptosis pathways by S32 in HeLa cells. S32, 1-[(3S,4R)-2,2-dimethyl-3-oxo-4-(2-piperidonyl)chroman-6-yl]-3-phenylurea; ROS, reactive oxygen species; $\Delta \Psi \mathrm{m}$, mitochondrial membrane potential.

slightly in a time-dependent manner (Fig. 9), demonstrating the activation of the caspase cascade. These results suggested that S32 induces apoptosis in HeLa cells primarily via the mitochondrial-mediated pathway.

\section{Discussion}

Cromakalim, a potassium channel opener, has been shown to have antitumor potential in human neuroblastoma and astrocytoma cell lines (15). The mechanism of this antitumor effect was suggested to involve the activation of ATP-sensitive
$\mathrm{K}^{+}$channels, leading to the inhibition of intracellular $\mathrm{Ca}^{2+}$ signaling (40). We previously reported that chroman analogs have a cytotoxic effect on HeLa cells and that phenylurea derivatives show a stronger effect than other chroman compounds (15). Among the phenylurea-including compounds, S32 showed the strongest cytotoxicity at a low concentration with an $\mathrm{IC}_{50}$ of $72.46 \mu \mathrm{M}$. In this study, we investigated the underlying mechanism attributed to the cell death induced by chroman analogs in human cervical carcinoma HeLa cells.

Various methods have been developed to monitor the different stages of the apoptotic pathway $(41,42)$. First, we 
assessed the morphological changes in the HeLa cells treated with S32. The apoptotic cell population increased with time after S32 treatment, and marked morphological changes indicated apoptosis. The results of the Annexin V-FITC/PI dual staining assay indicated that S32 induced early apoptosis in the HeLa cells in a time-dependent manner.

The cell cycle machinery tightly controls cell growth and the inhibition thereof (43), and dysregulation of cell cycle progression has been shown to be involved in the inhibition of apoptosis $(34,44)$. Flow cytometric analysis of the DNA content indicated that S32 induced G2-phase cell cycle arrest in HeLa cells, subsequently leading to an increase in the fraction of apoptotic cells. When DNA replication is blocked or if the template is damaged by radiation or other factors, signals are generated that can result in cell cycle arrest or apoptosis (45). Any cell that is damaged beyond the capacity of the DNA repair system is eliminated. The $\left[{ }^{3} \mathrm{H}\right]$-thymidine incorporation assay suggested that $\mathrm{S} 32$ inhibited DNA replication and cell proliferation in the HeLa cells.

ROS generation induces the depolarization of the MMP, thereby triggering a series of mitochondrial-mediated events including apoptosis (33). We found that S32-induced apoptosis in HeLa cells was associated with an early increase in intracellular ROS generation and depolarization of the MMP. These results prompted us to investigate the apoptotic pathway in S32-treated cells further by using western blot analysis. As ROS generation causes dimerization of Bax in the cytosol, ROS might be directly associated with apoptosis (46). The Bcl-2 family proteins Bcl-2 and Bax play crucial roles in the initiation of the mitochondrial-mediated apoptotic pathway (14). Bax activates cytochrome $c$ release into the cytosol, while $\mathrm{Bcl}-2$ prevents this by preserving mitochondrial integrity (46). The ratio of Bax to Bcl-2 was shown to be a determining factor in the induction of mitochondrial-mediated apoptosis in drug-induced apoptosis in hepatocellular carcinoma cells (47). We showed that S32 increased the ratio of $\mathrm{Bax} / \mathrm{Bcl}-2$, which may be involved in cell death initiation. The mitochondrial cytochrome $c$ release induces the formation of the apoptosome complex composed of Apaf-1 and caspase-9, which subsequently activates downstream caspases (11). In the present study, both caspase- 9 and -3 were found to be activated by treatment with S32, confirming that S32 induced apoptosis via the mitochondrial-mediated pathway. Based on the slight decrease in pro-caspase-8, we hypothesized that S32 additionally induced the extrinsic apoptotic pathway.

In the present study, we demonstrated that S32 inhibits proliferation of HeLa cells by inducing G2-phase cell cycle arrest and inhibiting DNA replication. In addition, S32 induces apoptosis by promoting ROS generation and MMP disruption (Fig. 10). Taken together, our results suggest that S32 triggers apoptosis mainly via the mitochondrial-mediated pathway, which can be further investigated in future studies, and our findings indicate that S32 has potential as an anticancer agent.

\section{Acknowledgements}

The authors would like to thank Dr Dong-Soo Shin (Changwon National University) for providing the chroman analogs.

\section{Funding}

This research study was supported by the 2016 Inje University research grant.

\section{Availability of data and materials}

The datasets used during the present study are available from the corresponding author upon reasonable request.

\section{Authors' contributions}

DKK and HJ conceptualized the study. DSS (Changwon National University) provided chroman analog samples. HJ performed the all of experiments. YS assisted the all of the experiments. All authors contributed to the data and analyses. HJ wrote the report. DKK and HJ reviewed and edited the manuscript. All authors read and approved the manuscript and agree to be accountable for all aspects of the research in ensuring that the accuracy or integrity of any part of the study are appropriately investigated and resolved.

\section{Ethics approval and consent to participate}

Not applicable.

\section{Consent for publication}

Not applicable.

\section{Competing interests}

Not applicable.

\section{References}

1. Parkin DM: Global cancer statistics in the year 2000. Lancet Oncol 2: 533-543, 2001

2. World Health Organization: Control of cancer of the cervix uteri: Review article based on a report of a WHO meeting, November 1985, Geneva. Bull World Health Organ 64: 607-618, 1986.

3. Yaoxian W, Hui Y, Yunyan Z, Yanqin L, Xin G and Xiaoke W: Emodin induces apoptosis of human cervical cancer HeLa cells via intrinsic mitochondrial and extrinsic death receptor pathway. Cancer Cell Int 13: 71, 2013.

4. Reed JC: Apoptosis-regulating proteins as targets for drug discovery. Trends Mol Med 7: 314-319, 2001.

5. Earnshaw WC: Nuclear changes in apoptosis. Curr Opin Cell Biol 7: 337-343, 1995.

6. Degterev A, Boyce M and Yuan J: A decade of caspases. Oncogene 22: 8543-8567, 2003.

7. Ziegler DS and Kung AL: Therapeutic targeting of apoptosis pathways in cancer. Curr Opin Oncol 20: 97-103, 2008.

8. Ehrlich E: Regulation of BAX mediated apoptosis by BCL2 family members. SABiosciences, 2011. https://www.qiagen.com /fi/spotlight-pages/newsletters-and-magazines/articles/reviewsonline-apoptosis/.

9. Reed JC and Green DR: Remodeling for demolition: Changes in mitochondrial ultrastructure during apoptosis. Mol Cell 9: 1-3, 2002.

10. Wang $\mathrm{C}$ and Youle RJ: The role of mitochondria in apoptosis. Annu Rev Genet 43: 95-118, 2009.

11. Ghobrial IM, Witzig TE and Adjei AA: Targeting apoptosis pathways in cancer therapy. CA Cancer J Clin 55: 178-194, 2005.

12. Marzo I, Brenner C, Zamzami N, Susin SA, Beutner G, Brdiczka D, Rémy R, Xie ZH, Reed JC and Kroemer G: The permeability transition pore complex: A target for apoptosis regulation by caspases and bcl-2-related proteins. J Exp Med 187: 1261-1271, 1998 . 
13. Kuwana T and Newmeyer DD: Bcl-2-family proteins and the role of mitochondria in apoptosis. Curr Opin Cell Biol 15: 691-699, 2003.

14. Gross A, McDonnell JM and Korsmeyer SJ: BCL-2 family members and the mitochondria in apoptosis. Genes Dev 13: $1899-1911,1999$

15. Zhang X, Zhao J, Kang S, Yi M, You S, Shin DS and Kim DK: A novel cromakalim analogue induces cell cycle arrest and apoptosis in human cervical carcinoma HeLa cells through the caspase- and mitochondria-dependent pathway. Int J Oncol 39: 1609-1617, 2011.

16. LeBlanc H, Lawrence D, Varfolomeev E, Totpal K, Morlan J, Schow P, Fong S, Schwall R, Sinicropi D and Ashkenazi A: Tumor-cell resistance to death receptor - induced apoptosis through mutational inactivation of the proapoptotic $\mathrm{Bcl}-2$ homolog Bax. Nat Med 8: 274-281, 2002.

17. Inal ME, Kanbak $G$ and Sunal E: Antioxidant enzyme activities and malondialdehyde levels related to aging. Clin Chim Acta 305: 75-80, 2001.

18. Le Bras M, Clément MV, Pervaiz S and Brenner C: Reactive oxygen species and the mitochondrial signaling pathway of cell death. Histol Histopathol 20: 205-219, 2005.

19. Fleury C, Mignotte B and Vayssière JL: Mitochondrial reactive oxygen species in cell death signaling. Biochimie 84: 131-141, 2002 .

20. Simon HU, Haj-Yehia A and Levi-Schaffer F: Role of reactive oxygen species (ROS) in apoptosis induction. Apoptosis 5: 415-418, 2000

21. Chan WH, Wu CC and Yu JS: Curcumin inhibits UV irradiation-induced oxidative stress and apoptotic biochemical changes in human epidermoid carcinoma A431 cells. J Cell Biochem 90: 327-338, 2003.

22. Jiang CP, Ding H, Shi DH, Wang YR, Li EG and Wu JH: Pro-apoptotic effects of tectorigenin on human hepatocellular carcinoma HepG2 cells. World J Gastroenterol 18: 1753-1764, 2012.

23. Sherr CJ: Cancer cell cycles. Science 274: 1672-1677, 1996.

24. Hartwell LH and Kastan MB: Cell cycle control and cancer. Science 266: 1821-1828, 1994.

25. Dictor M, Ehinger M, Mertens F, Akervall J and Wennerberg J: Abnormal cell cycle regulation in malignancy. Am J Clin Pathol 112 (Suppl 1): S40-S52, 1999.

26. Bonelli P, Tuccillo FM, Borrelli A, Schiattarella A and Buonaguro FM: CDK/CCN and CDKI alterations for cancer prognosis and therapeutic predictivity. BioMed Res Int 2014 361020, 2014.

27. Lu YJ, Yang SH, Chien CM, Lin YH, Hu XW, Wu ZZ, Wu MJ and Lin SR: Induction of G2/M phase arrest and apoptosis by a novel enediyne derivative, THDB, in chronic myeloid leukemia (HL-60) cells. Toxicol In Vitro 21: 90-98, 2007.

28. Goffin E, Lamoral-Theys D, Tajeddine N, de Tullio P, Mondin L, Lefranc F, Gailly P, Rogister B, Kiss R and Pirotte B: $\mathrm{N}$-Aryl-N'-(chroman-4-yl)ureas and thioureas display in vitro anticancer activity and selectivity on apoptosis-resistant glioblastoma cells: Screening, synthesis of simplified derivatives, and structure-activity relationship analysis. Eur J Med Chem 54: $834-844,2012$

29. Tominaga H, Ishiyama M, Ohseto F, Sasamoto K, Hamamoto T, Suzuki K and Watanabe M: A water-soluble tetrazolium salt useful for colorimetric cell viability assay. Anal Commun 36 47-50, 1999.

30. Bobyleva V, Pazienza TL, Maseroli R, Tomasi A, Salvioli S, Cossarizza A, Franceschi C and Skulachev VP: Decrease in mitochondrial energy coupling by thyroid hormones: A physiological effect rather than a pathological hyperthyroidism consequence. FEBS Lett 430: 409-413, 1998.
31. Lin SY, Liu JD, Chang HC, Yeh SD, Lin CH and Lee WS: Magnolol suppresses proliferation of cultured human colon and liver cancer cells by inhibiting DNA synthesis and activating apoptosis. J Cell Biochem 84: 532-544, 2002.

32. Qi F, Li A, Zhao L, Xu H, Inagaki Y, Wang D, Cui X, Gao B, Kokudo N, Nakata M, et al: Cinobufacini, an aqueous extract from Bufo bufo gargarizans Cantor, induces apoptosis through a mitochondria-mediated pathway in human hepatocellular carcinoma cells. J Ethnopharmacol 128: 654-661, 2010.

33. Park MT, Kim MJ, Kang YH, Choi SY, Lee JH, Choi JA, Kang CM, Cho CK, Kang S, Bae S, et al: Phytosphingosine in combination with ionizing radiation enhances apoptotic cell death in radiation-resistant cancer cells through ROS-dependent and -independent AIF release. Blood 105: 1724-1733, 2005.

34. Lee S, Christakos S and Small MB: Apoptosis and signal transduction: Clues to a molecular mechanism. Curr Opin Cell Biol 5: 286-291, 1993

35. Alenzi FQ: Links between apoptosis, proliferation and the cell cycle. Br J Biomed Sci 61: 99-102, 2004.

36. Cao W, Li XQ, Wang X, Fan HT, Zhang XN, Hou Y, Liu SB and Mei QB: A novel polysaccharide, isolated from Angelica sinensis (Oliv.) Diels induces the apoptosis of cervical cancer HeLa cells through an intrinsic apoptotic pathway. Phytomedicine 17: 598-605, 2010

37. Chen S, Cheng AC, Wang MS and Peng X: Detection of apoptosis induced by new type gosling viral enteritis virus in vitro through fluorescein annexin V-FITC/PI double labeling. World J Gastroenterol 14: 2174-2178, 2008.

38. Reed JC, Jurgensmeier JM and Matsuyama S: Bcl-2 family proteins and mitochondria. Biochim Biophys Acta 1366: 127-137, 1998.

39. Oltvai ZN, Milliman CL and Korsmeyer SJ: Bcl-2 heterodimerizes in vivo with a conserved homolog, Bax, that accelerates programmed cell death. Cell 74: 609-619, 1993.

40. Lee YS, Sayeed MM and Wurster RD: In vitro antitumor activity of cromakalim in human brain tumor cells. Pharmacology 49: 69-74, 1994.

41. Kiechle FL and Zhang X: Apoptosis: Biochemical aspects and clinical implications. Clin Chim Acta 326: 27-45, 2002.

42. Otsuki Y,LiZ and Shibata MA: Apoptotic detection methods - from morphology to gene. Prog Histochem Cytochem 38: 275-339, 2003.

43. Sánchez I and Dynlacht BD: New insights into cyclins, CDKs, and cell cycle control. Semin Cell Dev Biol 16: 311-321, 2005.

44. Smith DM, Gao G, Zhang X, Wang G and Dou QP: Regulation of tumor cell apoptotic sensitivity during the cell cycle (Review). Int J Mol Med 6: 503-507, 2000.

45. Zhang Y, Ahn EY, Jiang Y, Kim DK, Kang SG, Wu C, Kang SW, Park JS, Son BW and Jung JH: 3-Chloro-2,5-dihydroxybenzyl alcohol activates human cervical carcinoma HeLa cell apoptosis by inducing DNA damage. Int J Oncol 31: 1317-1323, 2007.

46. Hwang J, Yi M, Zhang X, Xu Y, Jung JH and Kim DK: Cytochalasin $\mathrm{B}$ induces apoptosis through the mitochondrial apoptotic pathway in HeLa human cervical carcinoma cells. Oncol Rep 30: 1929-1935, 2013.

47. Qi F, Inagaki Y, Gao B, Cui X, Xu H, Kokudo N, Li A and Tang W: Bufalin and cinobufagin induce apoptosis of human hepatocellular carcinoma cells via Fas- and mitochondria-mediated pathways. Cancer Sci 102: 951-958, 2011. 